\title{
ИЗУЧЕНИЕ ВЛИЯНИЯ УСЛОВИЙ ГОДА И ГЕНОТИПА НА ВАРИАБЕЛЬНОСТЬ И НАСЛЕДУЕМОСТЬ КОЛИЧЕСТВЕННОГО ПРИЗНАКА ВЫСОТА РАСТЕНИЯ И СВЯЗАННЫХ С НИМ ПРИЗНАКОВ У СОИ
}

\author{
Будак А., Харчук $O$. \\ Институт генетики, физиологии и защить растений. Кишинэу, Молдова. \\ e-mail:Sashabudak54@mail.ru
}

\begin{abstract}
The variability of traits is the height of the plant and the average length of the internode to a greater extent influenced by the genotype. The good heritability of these traits is evidenced by the high heritability rates for these traits.

The variability of the attachment height of the lower pod is more influenced by the conditions of the year, the heritability coefficient is lower than that of the previous traits. Genetic progress is the highest $(40.33 \%)$ among the studied traits in the trait with an average internode length, which indicates that selection for this trait may be the most successful.
\end{abstract}

Key words: soybean, heritability coefficient, genetic progress, plant height.

Введение
Соя - самая распространенная зернобобовая культура мирового значения. В семенах ее содержится в среднем 36-42\% полноценного белка, состоящего из глобулинов и небольшого количества альбуминов, 19-22\% полувысыхающего масла и до $30 \%$ углеводов. Белок характеризуется высокой усвояемостью, хорошей растворимостью в воде. В 1 кг семян сои 320-450 г протеина, 21 г лизина, 4,8 г метионина, 5,3 г цистеина и 4,9 г триптофана (1). Благоприятное сочетание питательных веществ позволяет широко возделывать сою как пищевое, кормовое и техническое растение. В последние годы, из-за упадка производства животноводческой продукции, дефицит пищевых белков усугубляется общим снижением платёжеспособного спроса населения. В то же время реализация населению готовых пищевых продуктов и полуфабрикатов на основе соевого белка по ценам в 3-5 раз ниже, чем их мясомолочные аналоги, позволяет обеспечить решение медикосоциальной проблемы белкового дефицита в питании. Благодаря богатому и разнообразному химическому составу соя нашла широкое применение при производстве около 1000 видов блюд и продуктов питания $(2,3)$.

Селекционная работа опирается на генетические исследования. Поэтому для выведения высокоурожайных сортов любой культуры для каждой почвенноклиматической зоны селекционеру необходимо знать информацию о типе наследования количественных признаков, числе генов, отвечающих за их проявление в фенотипе, силе генов и их локализации в хромосомах. Развитие каждого признака или свойства осуществляется на основе генотипа, протекает всегда при различающихся в той или иной степени внешних условиях. Поэтому наследственность любого признака или свойства всегда проявляется в форме различных модификаций (4). 


\section{Материалы и методы.}

С целью определения наследуемости и вариабельности количественных признаков сои, при взаимодействии в различные годы (двухфакторный анализ), были исследованы следующие параметры: генетическая $\left(g_{g}^{2}-\right.$ genetic variance $)$ и фенотипическая варианса $\left(g^{2}\right.$ ph-phenotypic variance), коэффициент наследуемости в широком смысле слова ( $h^{2}-$ heritability in broad sense), фенотипический (PCV,\% - phenotypic coefficients of variation,\%) и генотипический коэффициенты вариации (GCV,\% - genotypic coefficients of variation,\%), генетический прогресс (GA, \% - genetic advance, \%) [5,6]. Статистическая обработка данных была проведена в пакете программ STATISTICA Материалом для исследований послужили 5 генотипов сои, в 3-х кратной повторности в течении 3-х лет.

Лето за годы исследований в Республике Молдова было теплее обычного и с недобором осадков. Количество выпавших осадков за сезон с мая по август на наших полях составило от 42 мм до 95,4мм, что значительно меньше, чем среднемноголетнее количество по Кишинэу (таблицы 1,2).

Таблица 1. Количество выпавших осадков за сезон с мая по август 2017-2019

\begin{tabular}{|c|c|l|l|l|c|c|}
\hline Годы & май & июнь & июль & август & $\begin{array}{l}\text { Сумма за } \\
\text { 4 месяца }\end{array}$ & $\begin{array}{l}\text { Сумма за } \\
12 \text { месяцев }\end{array}$ \\
\hline $2017 *$ & 46,8 & 61,2 & 77,7 & 26,6 & 212,3 & 540,3 \\
\hline $2017 * *$ & 7,8 & 18,6 & 9,8 & 5,8 & 42,0 & 93,2 \\
\hline $2018^{*}$ & 23,9 & 105,7 & 91,1 & 6,6 & 227,3 & 532,8 \\
\hline $2018 * *$ & 8,4 & 58,4 & 26,2 & 2,4 & 95,4 & 97,6 \\
\hline $2019 *$ & 27,4 & 92,9 & 33,4 & 28,9 & 182,6 & 379,4 \\
\hline $2019 * *$ & 19,4 & 32,8 & 6,2 & 15,2 & 73,6 & 96,8 \\
\hline Средне многолетние & 48 & 66 & 64 & 56 & 234 & 542 \\
\hline
\end{tabular}

*Данные по Кишинэу. (https://www.weather-atlas.com/en/moldova/chisinau-weather-_may\#climate_text_1)

** Данные институтской метеостанции

Таблица 2. Максимальные температуры воздуха за летний период 2017-2019 годы

\begin{tabular}{|l|l|l|l|l|}
\hline годы & май & июнь & июль & август \\
\hline 2017 & 29,6 & 32,4 & 38,1 & 34,8 \\
\hline 2018 & 32,4 & 33,4 & 33,0 & 34,3 \\
\hline 2019 & 32,1 & 35,1 & 34,1 & 34,5 \\
\hline
\end{tabular}

\section{Результаты и их обсуждение}

Высота растения имеет большое значение, т.к. определяет технологичность сорта, влияет на устойчивость к полеганию, пригодность к механизированной уборке. Высокорослые сорта, как правило, дают более высокие урожаи по сравнению с карликовыми, низкорослыми сортами, но чаще полегают (7). Среди изученных нами генотипов имеются существенные различия в проявлении признака высота растения, в зависимости от влияния года только у одного генотипа (S-4x Nadejda). Высота растения у этого генотипа бала на уровне $51,7 \pm 1,9$ см в 2018 году, в 2017году (71,9 \pm 1,45 см) и 2019 году (74,03 $\pm 2,94$ см). Факториальным анализом установлена доля влияния года на вариабельность признака $29,54 \%$, а доля влияния генотипа значительно выше и составляет 64,21\%. Различия между генотипами по высоте 
растения отмечались во все годы изучения. Особенно эти различия проявились в 2018

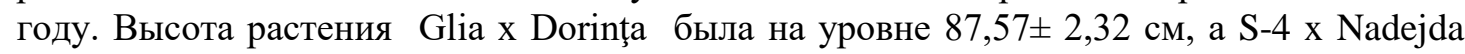
только 51,73 $\pm 1,91$ см, Deia и Glia x Dorinţa, S-4 x Nadejda. Взаимодействие генотип х год ниже $5,39 \%$, но тоже существенно. В остальные годы также отмечаются различия по этому признаку между генотипами. В 2017 году между Glia x Dorinţa и S-4 x Nadejda, Aura x Mida; S-4 x Nadejda и (Belosnejka x Charcovskaia 1367) x Lada; Aura x Mida и (Belosnejka x Charcovskaia 1367) х Lada. В 2018 году существенные различия по этому признаку отмечены только между двумя генотипами Glia x Dorinţa и Aura x Mida. Довольно низкое значение (таблица 5) PCV-GCV(\%) -0,47 свидетельствует о большом вкладе генотипа в проявлении признака. Коэффициент наследуемости в широком смысле по этому признаку $\mathrm{h}^{2}$ довольно высок $(0,96)$, что свидетельствует о хорошей наследуемости этого признака.

По признаку - высота прикрепления нижнего боба, у которого отмечается средняя положительная связь с высотой растения (1), доля влияния генотипа на изменчивость ниже $-36,16 \%$, а влияние года выше $55,20 \%$. Взаимодействие генотипа на год по этому признаку не существенно. В зависимости от условий года, отмечены существенные различия в проявлении этого признака у следующих генотипов: Glia x Dorinţa, в 2018 году высота прикрепления нижнего боба была ниже $10,4 \pm 0,76 \mathrm{~cm}$, чем в остальные годы $15,2 \pm 0,25 \mathrm{~cm}$ и $15,03 \pm 0,73 \mathrm{~cm}$; y Aura x Mida, также отмечено снижение по этому признаку в этом же году.

Таблица 3. Характеристика генотипов по высоте растения, высоте прикрепления нижнего боба и средней длины междоузлия

\begin{tabular}{|c|c|c|c|c|}
\hline Генотип & Год & $\begin{array}{c}\text { Высота } \\
\text { растения, см. }\end{array}$ & $\begin{array}{c}\text { Высота } \\
\text { прикрепления } \\
\text { нижнего боба, см }\end{array}$ & $\begin{array}{c}\text { Средняя } \\
\text { Длина } \\
\text { Междоузлия, см }\end{array}$ \\
\hline Deia & 2017 & $69.6 \pm 3,9$ & $16,67 \pm 1,03$ & $5,82 \pm 0,12$ \\
\hline,,-- & 2018 & $63.4 \pm 1,8$ & $15,03 \pm 0,73$ & $5,57 \pm 0,15$ \\
\hline,,-- & 2019 & $72.7 \pm 1,9$ & $17,07 \pm 1,23$ & $5,47 \pm 0,09$ \\
\hline Glia x Dorinţa & 2017 & $86.03 \pm 1,7$ & $15,2 \pm 0,25$ & $6,67 \pm 0,22$ \\
\hline,,-- & 2018 & $87.57 \pm 1,3$ & $10,4 \pm 0,76$ & $5,85 \pm 0,33$ \\
\hline,,-- & 2019 & $84.9 \pm 1,9$ & $15,03 \pm 0,73$ & $5,69 \pm 0,17$ \\
\hline S-4 х Nadejda & 2017 & $71.9 \pm 0,8$ & $14,5 \pm 1,54$ & $4,76 \pm 0,06$ \\
\hline,,-- & 2018 & $51.73 \pm 1,1$ & $12,66 \pm 1,46$ & $3,87 \pm 0,23$ \\
\hline,,-- & 2019 & $74.03 \pm 1,9$ & $16,0 \pm 0,53$ & $5,11 \pm 0,20$ \\
\hline Аura х Мida & 2017 & $65.67 \pm 1,0$ & $17,07 \pm 1,42$ & $5,48 \pm 0,06$ \\
\hline,,-- & 2018 & $57.76 \pm 1,8$ & $9,43 \pm 1,48$ & $4,36 \pm 0,15$ \\
\hline,,-- & 2019 & $64.27 \pm 1,9$ & $13,4 \pm 0,86$ & $4,69 \pm 0,14$ \\
\hline (Белоснежка х & 2017 & $81.97 \pm 11$ & $18,67 \pm 1,96$ & $6,32 \pm 0,19$ \\
\hline Харьк. 1327) х Лада & & & & \\
\hline,,-- & 2018 & $71.9 \pm 3,3$ & $16,23 \pm 1,09$ & $5,44 \pm 0,11$ \\
\hline,,-- & 2019 & $82.8 \pm 1,4$ & $20,73 \pm 1,47$ & $6,10 \pm 0,14$ \\
\hline
\end{tabular}


Таблица 4. Факториальный анализ вариабельности высоты растения, высоты прикрепления нижнего боба и средней длины междоузлия при взаимодействии генотипа и года

\begin{tabular}{|l|c|l|l|c|l|c|c|}
\hline & \multicolumn{3}{|c|}{ Высота растения } & \multicolumn{2}{c|}{$\begin{array}{l}\text { Высота } \\
\text { прикрепления } \\
\text { нижнего боба }\end{array}$} & \multicolumn{2}{c|}{$\begin{array}{l}\text { Средняя длина } \\
\text { междоузлия }\end{array}$} \\
\hline $\begin{array}{l}\text { Источни } \\
\text { к } \\
\begin{array}{l}\text { вариабе- } \\
\text { льности }\end{array}\end{array}$ & $\begin{array}{l}\text { Степень } \\
\text { свобод } \\
\text { ы }\end{array}$ & $\begin{array}{l}\text { Сумма } \\
\text { квадра } \\
\text { тов }\end{array}$ & $\begin{array}{l}\text { Вклад в } \\
\text { источник } \\
\text { вариабель } \\
\text {-ности, } \%\end{array}$ & $\begin{array}{l}\text { Сумма } \\
\text { квадра } \\
\text { тов }\end{array}$ & $\begin{array}{l}\text { Вклад в } \\
\text { источник } \\
\text { вариабель } \\
\text {-ности, } \%\end{array}$ & $\begin{array}{l}\text { Сумма } \\
\text { квадра } \\
\text {-тов }\end{array}$ & $\begin{array}{l}\text { Вклад в } \\
\text { источник } \\
\text { вариабе- } \\
\text { льности, } \\
\%\end{array}$ \\
\hline $\begin{array}{l}\text { Генотип } \\
\text { сои }\end{array}$ & 4 & $867,2^{*}$ & 64,21 & $43,96^{*}$ & 36,16 & $3,82^{*}$ & 57,37 \\
\hline Год & 2 & $399,0^{*}$ & 29,54 & $67,10^{*}$ & 55,20 & $2,38^{*}$ & 35,71 \\
\hline $\begin{array}{l}\text { Генотип } \\
\text { х год }\end{array}$ & 8 & $72,8^{*}$ & 5,39 & 6,25 & 5,14 & 0,34 & 5,04 \\
\hline $\begin{array}{l}\text { Остаточ- } \\
\text { ные } \\
\text { эффекты }\end{array}$ & 30 & 11,4 & 0,84 & 4,25 & 3,49 & 0,12 & 1,86 \\
\hline
\end{tabular}

Генотипическая и фенотипическая вариансы высоты прикрепления нижнего боба значительно ниже, чем по предыдущему признаку. Следовательно, генотипы, использовавшиеся в анализе, не столь существенно различались по этому признаку. Влияние условий различных лет испытания на вариабельность по этому признаку выше, а взаимодействие года и генотипа еще ниже. Разница между генотипическим и фенотипическим коэффициентом вариации 3,58 \%. Довольно низкая разница говорит о том, что сорт оказывает существенное влияние на проявление признака высота прикрепления нижнего боба, но значительно меньше, чем по признаку высота растения. Коэффициент наследуемости в широком смысле слова довольно высок $\mathrm{h}^{2}=0.76$, что свидетельствует о хорошей наследуемости этого признака, но намного ниже, чем по высоте растения. Генетический прогресс при 5\%- ном селекционном дифференциале был на уровне $29,64 \%$.

Таблица 5. Вариабельность и наследуемость признака высота растения и признаков связанных с ним

\begin{tabular}{|l|l|l|l|l|l|l|l|l|}
\hline Признаки & \multicolumn{9}{|c|}{ Параметры } \\
\cline { 2 - 10 } & $\mathrm{G}_{\mathrm{g}}^{2}$ & $\mathrm{G}_{\mathrm{ph}}^{2}$ & $\mathrm{~h}^{2}$ & $\begin{array}{l}\mathrm{GCV}, \\
\%\end{array}$ & PCV,\% & $\begin{array}{l}\text { PCV,\%- } \\
\mathrm{GCV}, \%\end{array}$ & $\mathrm{GA}$ & GAM,\% \\
\hline Высота растения & 285,27 & 296,67 & 0,96 & 23,32 & 23,79 & 0,47 & 21,48 & 29,64 \\
\hline $\begin{array}{l}\text { Высота нижнего } \\
\text { боба }\end{array}$ & 13,23 & 17,49 & 0,76 & 23,94 & 27,52 & 3,58 & 5,19 & 34,16 \\
\hline $\begin{array}{l}\text { Средняя длина } \\
\text { междоузлия }\end{array}$ & 1,232 & 1,356 & 0,908 & 20,63 & 21,63 & 1,00 & 2,17 & 40,33 \\
\hline
\end{tabular}

Дисперсионным анализом установлено, что доля генотипа на вариабельность признака средняя длина междоузлия составляет 57,37\%. Генотипы различаются по этому признаку в течении одного года. Влияние года также существенно и составляет 37,71\%. К примеру, у S-4 x Nadejda и Aura x Mida. Взаимодействие генотип на год 
5,04\%. Разница PCV,\%-GCV,\% составляет всего 1\%. Это выше, чем по признаку высота растения, что говорит о том, что на этот признак значительно влияет генотип. Коэффициент наследуемости в широком смысле $\mathrm{h}^{2}=0.908$, а генетический прогресс самый высокий 40,33\% среди изучавшихся признаков

\section{Выводы}

На вариабельность признаков высота растения и средняя длина междоузлия в большей степени влияет генотип. О хорошей наследуемости этих признаков свидетельствуют высокие коэффициенты наследуемости по этим признакам.

На вариабельность высоты прикрепления нижнего боба в большей степени влияют условия года, коэффициент наследуемости ниже, чем у предыдущих признаков. Генетический прогресс самый высокий 40,33\% среди изучавшихся признаков у признака средняя длина междоузлия, это свидетельствует о том, что селекция по этому признаку может быть наиболее успешной.

\section{Библиография}

1. Вершинин А.Н. Изменчивость признаков продуктивности растений сои и анализ их наследования. Автореферат диссертации на соискание ученой степени кандидата сельскохозяйственных наук. Зерноград 2012.http://earthpapers.net/izmenchivost-priznakov-produktivnosti-rasteniy-soi-ianaliz-ih-nasledovaniya\#ixzz6UiX92VvE

2. Кадыров С. В., Черникова Г. Г. Соя и здоровое питание. / Воронеж: ВГАУ, 1998. $-51 \mathrm{c}$.

3. Бородин Е.А, Аксенова Т. В., Анищенко Н. И. Пищевые продукты из сои. Новая роль. / // Вестник ДВО РАН. - 2000. №5.-С. 72-85.

4. Присяжнюк О.И., Димитров В.Г., Мартынов А.М. Прогнозирование фенотипической продуктивности средне-ранних сортов сои. //Сортови вчення та охрана прав на рослин. 2017. Т.13 №2. C.167-171. ISSN 2518-1017.

5. Adeniji O.T. Cenetic variation and heritability for foliage yield and yield component traits in edible Amaranthus cruentus [L.] genotypes. Bangladdesh J. Agrical. Res. 2018; 43(3):513-524.

6. Balcan A. Genetic variability, heritability and genetic advance for yield and quality traits in M2-4 generations of bread whe 